\title{
A RANDOMISED CONTROLLED TRIAL TO COMPARE THE EFFECTS OF TWO METHODS OF PRE- OPERATIVE HAIR REMOVAL ON SURGICAL SITE INFECTIONS IN PATIENTS UNDERGOING ELECTIVE TYMPANOPLASTY
}

\author{
Kirthana Rebecca Jacob ${ }^{1}$, Anil Markose P2, Anna Mathew ${ }^{3}$, Jacob C. E 4
}

${ }^{1}$ House Surgeon, Department of ENT, MOSC Medical College, Kolenchery, Ernakulam, Kerala, India.

${ }^{2}$ Associate Professor, Department of ENT, MOSC Medical College, Kolenchery, Ernakulam, Kerala, India.

3Professor, Department of Pharmacology, MOSC Medical College, Kolenchery, Ernakulam, Kerala, India.

4 Professor, Department of ENT, MOSC Medical College, Kolenchery, Ernakulam, Kerala, India.

\section{BACKGROUND}

ABSTRACT

From time immemorial, ever since the principles of disinfection were being brought into being, it has been noticed that it is the seemingly simple and easy steps that brought giant breakthroughs in infection control. For example, the introduction of alcoholbased handrub by health care workers in a hospital in central India gave a complete reduction in the bacterial flora in the hands.[1] Similarly, preparation of surgical site before skin incision has been the convention. Skin preparation is done by disinfecting the area with a cleaning solution (soap, spirit, povidone-iodine). Staphylococcus aureus is the commonest organism in site infection.

Aim- This randomised controlled trial was planned to evaluate which method of pre-operative hair removal, clipping or shaving is less likely to cause surgical site infection.

\section{MATERIALS AND METHODS}

Consenting patients undergoing tympanoplasty were randomised by permuted block randomisation to pre-operative hair removal by shaving or clipping with allocation concealment from the investigator. A blinded ass essor used the ASEPSIS scoring method to grade the wound healing.

\section{RESULTS}

Of the 64 patients undergoing tympanoplasty enrolled into the study 62 showed satisfactory healing when graded by the ASEPSIS score and 2 (3.1\%) had disturbances of healing, while there were no incidents of mild, moderate or severe surgical site infection. Though both incidents of delayed wound healing were in the group where hair removal was done by shaving. No significance could be attributed to these findings.

\section{CONCLUSION}

Though two subjects developed disturbances in healing, they could be treated and could go home by the seventh day. There were no patients who had mild, moderate or severe surgical site infection as graded by the ASEPSIS score. This shows that good preoperative preparation and strict enforcement of aseptic precautions can reduce the number of surgical site infections irrespective of the method of hair removal.

\section{KEY WORDS}

Surgical Site Infection (SSI), Pre-Operative Skin Preparation, Hair Removal, Shaving, Clipping, Healing, ASEPSIS Score.

HOW TO CITE THIS ARTICLE: Jacob KR, Markose AP, Mathew A, et al. A randomised controlled trial to compare the effects of two methods of pre-operative hair removal on surgical site infections in patients undergoing elective tympanoplasty. J. Evolution Med. Dent. Sci. 2018;7(37):4095-4101, DOI: 10.14260/jemds/2018/916

\section{BACKGROUND}

From time immemorial ever since the principles of disinfection were being brought into being, it has been noticed that it is the seemingly simple and easy steps that brought giant breakthroughs in infection control. For example, the introduction of alcohol-based handrub by health care workers in a hospital in central India gave a complete reduction in the bacterial flora in the hands.[1]

'Financial or Other Competing Interest': None.

Submission 03-01-2018, Peer Review 24-08-2018,

Acceptance 31-08-2018, Published 10-09-2018.

Corresponding Author:

Dr. Jacob C. E,

Department of ENT,

MOSC Medical College,

Kolenchery,

Kerala, India.

E-mail: jacobchundamannil68@gmail.com

DOI: $10.14260 / \mathrm{jemds} / 2018 / 916$
Similarly, preparation of surgical site before skin incision has been the convention. Skin preparation is done by disinfecting the area with a cleaning solution (Soap, Spirit, Povidone-Iodine). Staphylococcus aureus is the commonest organism in site infection, at times methicillin resistant (MRSA).[2]

The common methods used for pre-op skin preparation are shaving with razor, hair clipping with scissors and the use of depilatory cream. A systematic review published in Cochrane database by Tanner et al reveal three studies, which conclude that preoperative shaving is definitely associated with more surgical site infection compared to hair clipping. [3] They also studied pre-operative preparation on the day of surgery with that done on the previous day. But there seemed to be no statistical significance between the two arms in terms of timing of the preparation. They also did not find any difference between the use of depilatory creams compared to shaving. An Italian study by Orsi et al suggests that hair 
removal should be done immediately before surgery and not in advance, in order to reduce the rate of infections.[4]

Chronic Suppurative Otitis Media (CSOM) of the tubotympanic type, is a widely prevalent condition in ENT. It is likely that the commonest procedure on operation theatre lists in any hospital in South India would be tympanoplasty. Although, this operation can be performed under local anaesthesia also if need be. In our centre, only general anaesthesia is used keeping in mind the comfort of the patient who has to lie down for a procedure lasting almost two hours. Post-aural or William Wilde's incision is extremely versatile, providing good access to the middle ear, even in patients with a narrow external auditory canal and short neck. Therefore, this incision was used for all patients.

Skin preparation is defined as the removal of as many bacteria from the patient's skin through shaving, washing and chemical disinfection. The purpose of skin preparation is to reduce the number of micro-organisms in the field of operation and prevent infection. Hair is removed as its presence can interfere with the exposure and subsequent surgical procedure, the suturing of the incision and the application of drapes and dressing.[5] Hair removal should be performed on the day of surgery, in a location outside of the operating theatre or procedure room. Only hair interfering with the surgical procedure should be removed.[6]

\section{Hair Removal can be done in Three Ways- \\ 1. Shaving with a Razor}

This is the most common and cheapest method of hair removal. This method uses a sharp blade, held within the head of a razor, which is drawn over the patient's skin to cut hair close to the skin surface.

\section{Clipping with Scissors}

The use of clippers with fine teeth to cut hair close to the patient's skin, leaving a short stubble of usually around one millimetre in length. Heads of clippers are disposable or disinfected between patients to minimise the risk of cross-infections.

\section{Depilatory Creams}

Depilatory creams are chemicals that dissolve the hair. This is a more time-consuming process than shaving or clipping as the cream has to remain in contact with the hair between five and twenty minutes.

A prospective randomised study carried out to compare the effect of pre-operative shaving with chemical depilation on wound infection in 100 patients showed they were safe and effective and that depilatory creams saved time for preoperative preparation and had an advantage in areas where shaving was difficult.[5] In a comparative study between the two pre-operative skin preparations (shaving and depilatory creams): SSI rate was $5.6 \%$ in patients who underwent shaving compared with a $0.6 \%$ rate among those who used depilatory cream. ${ }^{[8]}$ However, we decided not to use depilatory creams because of the risk of irritant or allergic reactions to the cream and the need to carry out patch 24 hours before the cream is applied. Mangram et al reviewed two studies comparing shaving and clipping (Balthazar 1981; Alexander 1983) and found that clipping was favoured over shaving on the morning of the operation $(p=.006) .[7]$ The guidelines for hand washing as described in the manuscript on surgical hand preparation by the WHO (2015) were strictly followed for all the surgeries included in this study. ${ }^{[8]}$
Pre-operative skin preparation was carefully performed using antiseptics in all patients as per routine hospital procedure to remove all contamination. ${ }^{[9]}$

The International Nosocomial Infection Control Consortium (INICC) studied surgical site infection rates in six cities of India in 325 women randomised to antibiotic prophylaxis [with $2 \mathrm{~g}$ of cloxacillin intravenously (IV) or 600 mg of clindamycin IV] (Intervention group) or no antibiotic prophylaxis (control group). The follow-up done at one and two weeks post-operatively documented all post-operative infections using a graded scale. A larger percentage of participants from the control group developed infection compared to the intervention group, but this was not statistically significant.[10] A review of literature by Gagliardi et al revealed several strategies that antibiotic prophylaxis reduce SSI rates.[11] In our study, all patients received cloxacillin $500 \mathrm{mg}$, which was given sixth hourly one day prior to seven days post-operative.

Surgical Site Infections (SSIs) are either superficial incisional, deep incisional or organ/ space infections. The presence of infection may include at least one of the following: pus, pain, tenderness, swelling or redness.

There are several definitions of SSI and the diagnosis of infection varies between surgeons. There is a need for all doctors concerned using the same method for diagnosing surgical site infection.[12] The ASEPSIS score, compiled by Wilson et al, is a validated tool to assess surgical site infection (SSI).[13] It classifies wound healing into satisfactory and disturbed healing and mild, moderate and severe surgical site infection. Therefore, this randomised controlled trial was planned to evaluate two methods of hair removal to see if there is a significant difference in the ASEPSIS scores of the patients who had the surgical site hair removal by clipping or shaving. All other steps were standardised to protocol and subjects were assigned to two groups- hair removal by clipping with scissors and shaving with a razor to find out which method is associated with a greater incidence of surgical site infection associated with this procedure.

\section{Objectives}

To determine if the method of hair removal, clipping with scissors or shaving with razor affects the incidence of Surgical Site Infections (SSI) as measured by the ASEPSIS score in patients having elective tympanoplasty in a rural tertiary care centre.

\section{MATERIALS AND METHODS}

This is a parallel group, randomised controlled trial on subjects undergoing elective tympanoplasty during the period from May $15^{\text {th }}$ to July $15^{\text {th }} 2015$, to compare two modes of surgical site hair removal. Permission for the study was obtained from the Medical Superintendent and the study was approved by the Institutional Review Board and the Institutional Ethics Committee. The study was also registered with the CTRI prior to commencement.

Patients diagnosed to have chronic suppurative otitis media between the ages of 10 and 70 years of tubotympanic type posted for elective tympanoplasty using post-aural incision (William Wilde's incision) under general anaesthesia who gave written informed consent were enrolled serially to participate in the study. Demographic data and details regarding diagnosis, co-morbidities and medications were recorded after the patient's interview. 
After preparation, the participants were assigned to one of the two arms of the study Group A or Group B by computer-based permuted block randomisation using a block size of four. In the first arm, Group A, the post-aural hair clipping is done only with scissors (Razor not used) twelve hours prior to incision time. In the second arm, Group B, the post-aural hair is shaved twelve hours prior to incision time as is routinely done in this department. The allocation was concealed from the investigator.

\section{The Sample Size required was taken for Convenience Preparation of Patients}

The Participants were prepared for a Period of Two Weeks as follows-

1. The ear was kept dry after appropriate suction clearance in the outpatient department.

2. Peri-operative cover included cloxacillin $500 \mathrm{mg}$ sixth hourly from first pre-operative day upto seven days post-operatively as per protocol followed in our hospital.

3. The nurse in charge of pre-operative preparation in the general surgery ward followed strict aseptic measures before skin preparation of the patient by washing (Scrubbing) hands following the standard protocol and wearing sterile gloves.

4. The participants were then randomised to one of the two groups- Group A: Hair removal with razor and Group B: Hair clipping with clippers.

5. Twelve hours prior to surgery, the area of two fingerbreadth above the pinna was cleaned with povidoneiodine and the hair in a rectangular area of $2 \mathrm{~cm} \mathrm{x} 1 \mathrm{~cm}$ was then either shaved or clipped. Following hair removal, every patient is asked to wash his/ her head with shampoo.

6. On the table after induction of general anaesthesia, the area is scrubbed with povidone-iodine and draped. Similarly, following suturing of incision site, the area is cleaned using povidone-iodine solution and povidoneiodine ointment is applied before the mastoid bandage is placed.

\section{Follow-Up of Patients}

The bandage is removed, and the wound inspected on the third post-operative day, then re-bandaged and removed on the seventh post-operative day, if there are no signs of infection of incision site (redness, local rise in temperature, swelling, purulent or serous discharge, wound gape, separation of deeper tissues or high-grade fever). The patient was advised to refrain from washing their hair during this period. The details of hair removal are collected from the records on the day of surgery. The wound assessments were done using the ASEPSIS scoring system.

\section{Statistical Analysis}

The qualitative data was expressed by Chi-square test. Fisher's test was used. For statistical analysis, SPSS software version 25 was used.

\section{The Outcome Measure- ASEPSIS Score}

The surgical site is inspected, and the wound is scored based on the findings of serous exudate, erythema, purulent exudate and separation of deep tissue. Additional information on wound treatments, culture findings and delayed discharge are then obtained and the ASEPSIS score is calculated.[14]
The ASEPSIS scoring system has been used to quantitate post-operative wound infections. It was initially designed for evaluating the effectiveness of antibiotic prophylaxis prior to cardiac surgery, but has been proposed as a method to compare care of wounds at different institutions. It was developed at the Middlesex and University College (London) Hospitals in England.

The ASEPSIS score, prepared and validated by Wilson et al uses the seven parameters to score the surgical site infection. These constitute the acronym ASEPSIS.

A. Additional treatment with antibiotics, pus drainage under local and/ or wound debridement under general anaesthesia; S. Serous discharge; E. Erythema; P. Purulent exudate; S. Separation of deeper tissues; I. Isolation of bacteria; S. Stay as inpatient prolonged.

\section{Calculation of the ASEPSIS Score}

The ASESPSIS score is = SUM (Points from wound inspection parameters) + (Points for antibiotics) + (points of pus drainage + (Points for wound debridement) + (Points for bacterial isolation $)+$ (Points for prolonged hospitalisation) .

Table 1. Interpretation of the ASEPSIS Score

- Minimum score: 0 • Maximum score: 70

\begin{tabular}{|c|c|}
\hline ASEPSIS Score & ASEPSIS Category \\
\hline $0-10$ & Satisfactory healing \\
\hline $11-20$ & Disturbance of healing \\
\hline $21-30$ & Minor wound infection \\
\hline $31-40$ & Moderate wound infection \\
\hline$>40$ & Severe wound infection \\
\hline \multicolumn{2}{|c|}{ Table 1. Interpretation ofthe ASEPSIS Score } \\
\hline
\end{tabular}

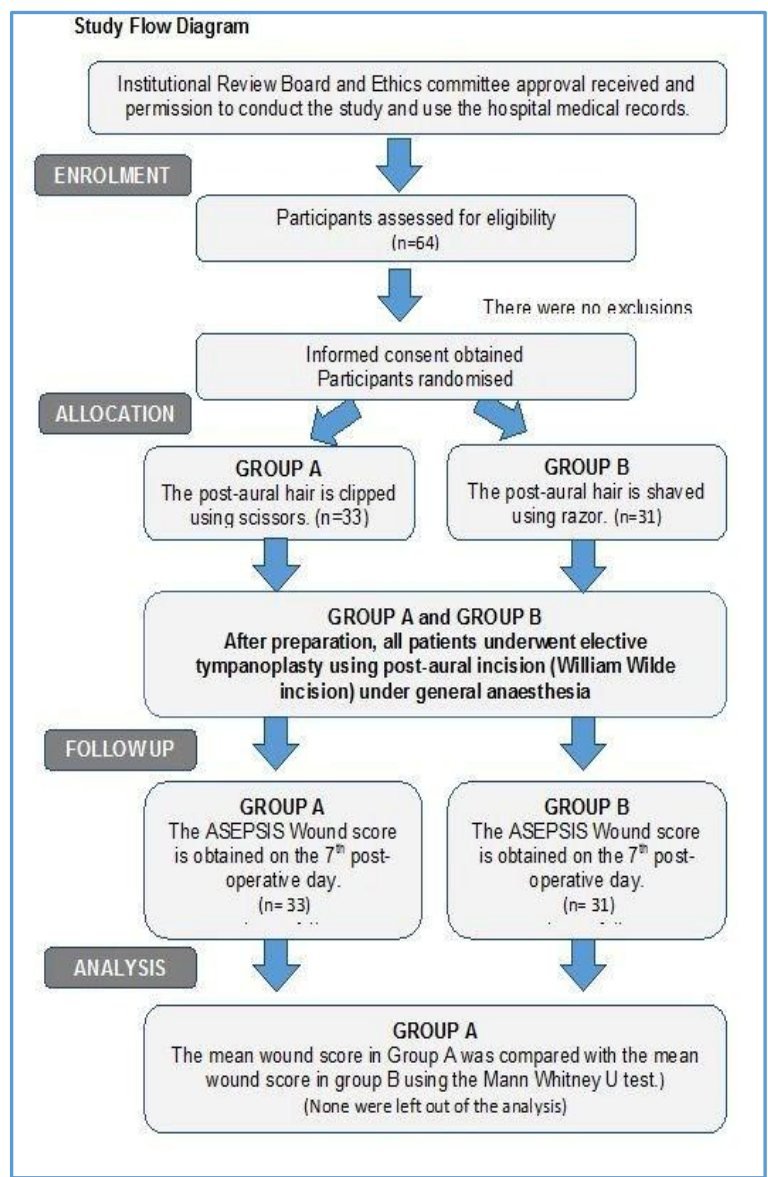

Figure 1. Consort Flow Chart 


\section{RESULTS}

In the two-month period during which this randomised controlled trial was conducted, 64 patients of whom 46 were females and 18 were males underwent elective tympanoplasty in this tertiary care centre. All gave written informed consent and were serially recruited and randomised to Group A or Group B. The majority of participants were adults (87.5\%) and 51 (79.6\%) were married and all except one had satisfactory wound healing. Of the $8(12.5 \%)$ participants below the age of 20 years, one had disturbed wound healing. Thus, the incidence of disturbed wound healing in this group of 64 patients was $3.1 \%$.

Most of the participants belonged to the high and middle income group (43 [67.2\%]), while 21 participants belonged to the low socioeconomic group. Both the participants who developed SSI belonged to the low income group (9.5\%). Out of the 64 participants, 49 (76.5\%) did not consume alcohol or smoke and 31 (48.4\%) were free from any co-morbidity and one each from each of these groups developed SSI. There were 12 hypertensive participants and seven diabetic patients undergoing treatment. Haemoglobin levels in all participants except three were over $12 \mathrm{~g} \%$. Both the participants who developed infection had haemoglobin levels over $13 \mathrm{~g} \%$.

Twenty four subjects were diagnosed to have left-sided Chronic Suppurative Otitis Media (CSOM), 28 had right-sided CSOM and 12 patients had bilateral CSOM. The demographic parameters were comparable in the two arms of this study. When the two groups were compared, they were found to be homogeneous indicating good randomisation.

Of the 64 participants 30 underwent left-sided tympanoplasty and both the cases of SSI were in this category, while 34 had a right-sided tympanoplasty and there were no incidents of SSI in this group. The baseline characteristics of participants in the two groups are given in Table 2 .

\begin{tabular}{|c|c|c|c|c|}
\hline Characteristic & Category & Group A & Group B & Total \\
\hline \multirow{2}{*}{ Gender } & \multirow{2}{*}{$\begin{array}{l}\text { Female } \\
\text { Male }\end{array}$} & $24(52.17 \%)$ & $22(47.83 \%)$ & 46 \\
\hline & & $9(50 \%)$ & $9(50 \%)$ & 18 \\
\hline \multirow[t]{4}{*}{ Age } & $<20$ years & $6(75 \%)$ & $2(25 \%)$ & 8 \\
\hline & 20-39 years & $11(45.83 \%)$ & $13(54.17 \%)$ & 24 \\
\hline & 40-59 years & $12(46.15 \%)$ & $14(53.85 \%)$ & 26 \\
\hline & 60 and above & $4(66.67 \%)$ & $2(33.33 \%)$ & 6 \\
\hline \multirow{3}{*}{ Religion } & \multirow{3}{*}{$\begin{array}{c}\text { Christian } \\
\text { Hindu } \\
\text { Muslim }\end{array}$} & $15(50 \%)$ & $15(50 \%)$ & 30 \\
\hline & & $8(53.34 \%)$ & $7(46.67 \%)$ & 15 \\
\hline & & $10(52.63 \%)$ & $9(47.37 \%)$ & 19 \\
\hline \multicolumn{5}{|l|}{$\begin{array}{c}\text { Socio- } \\
\text { Economic }\end{array}$} \\
\hline \multirow[t]{3}{*}{ Status } & Low & $11(52.38 \%)$ & $10(47.67 \%)$ & 21 \\
\hline & Middle & $17(50 \%)$ & $17(50 \%)$ & 34 \\
\hline & High & $5(55.56 \%)$ & $4(44.44 \%)$ & 9 \\
\hline \multicolumn{5}{|l|}{ Related } \\
\hline \multirow{5}{*}{ Factors } & \multirow{4}{*}{$\begin{array}{c}\text { None } \\
\text { Alcohol } \\
\text { Smoking } \\
\text { Smoking and }\end{array}$} & $26(53.06 \%)$ & $23(46.94 \%)$ & 49 \\
\hline & & $2(40 \%)$ & $3(60 \%)$ & 5 \\
\hline & & $2(28.57 \%)$ & $5(71.43 \%)$ & 7 \\
\hline & & & & \\
\hline & Alcohol & $3(100 \%)$ & 0 & 3 \\
\hline \multicolumn{5}{|l|}{ Co- } \\
\hline \multirow[t]{11}{*}{ morbidities } & None & $16(51.62 \%)$ & $15(48.38 \%)$ & 31 \\
\hline & Diabetes Mellitus (DM) & & & \\
\hline & & $3(42.86 \%)$ & $4(57.14 \%)$ & 7 \\
\hline & Hypertension (HTN) & $7(58.33 \%)$ & $5(41.67 \%)$ & 12 \\
\hline & Both DM and HTN & $2(28.57 \%)$ & $5(71.43 \%)$ & 7 \\
\hline & DM and & & & \\
\hline & Hyperthyroidism & $1(100 \%)$ & 0 & 1 \\
\hline & HTN and & & & \\
\hline & Hyperthyroidism & $1(100 \%)$ & 0 & 1 \\
\hline & DM and Dyslipidaemia & 0 & $1(100 \%)$ & 1 \\
\hline & Others & $3(75 \%)$ & $1(25 \%)$ & 4 \\
\hline \multirow{2}{*}{ Marital Status } & \multirow{2}{*}{$\begin{array}{c}\text { Married } \\
\text { Unmarried }\end{array}$} & $23(45.10 \%)$ & $28(54.90 \%)$ & 51 \\
\hline & & $10(76.92 \%)$ & $3(23.08 \%)$ & 13 \\
\hline \multirow{4}{*}{ Haemoglobin } & \multirow{4}{*}{$\begin{array}{l}\quad<12 \mathrm{~g} \% \\
12-12.9 \mathrm{~g} \% \\
13-13.9 \mathrm{~g} \% \\
14 \mathrm{~g} \% \text { and above }\end{array}$} & $2(66.67 \%)$ & $1(33.33 \%)$ & 3 \\
\hline & & $14(63.63 \%)$ & $8(36.36 \%)$ & 22 \\
\hline & & $13(43.33 \%)$ & $17(56.67 \%)$ & 30 \\
\hline & & $4(44.44 \%)$ & $5(55.56 \%)$ & 9 \\
\hline \multirow[t]{3}{*}{ Diagnosis } & Left CSOM & $17(70.83 \%)$ & $7(29.17 \%)$ & 24 \\
\hline & Right CSOM & $9(32.14 \%)$ & $19(67.86 \%)$ & 28 \\
\hline & Bilateral CSOM & $7(58.34 \%)$ & $5(41.66 \%)$ & 12 \\
\hline
\end{tabular}


Of the 64 consenting participants 33 were randomised to Group A where skin was prepared by clipping with scissors and 31 participants to Group B where skin was prepared by shaving with a razor. Of the 33 subjects who had skin preparation done by clipping method, all had an ASEPSIS score less than 10 indicating satisfactory healing and out of 31 subjects who had hair removal by shaving, two had scores over 10 indicating a disturbed healing process in $6.5 \%$ of the 31 subjects in this group. In both the subjects who had disturbance of healing, the skin preparation was done by shaving with razor. However, when the two groups were compared using the Mann-Whitney U test, the difference was not statistically significant $(\mathrm{p}=0.141)$.

Regarding duration of surgery, 51 (79.6\%) patients had surgery lasting less than two hours and both patients who developed SSI belonged to this group. Thirteen patients had surgery lasting more than 2 hours duration.

Of the 53 patients who had wound irrigation with saline only two persons (3.8\%) developed infection, while all the 11 subjects whose wound was irrigated with both saline and betadine (10\% povidone-iodine) had ASEPSIS scores less than 10 indicating satisfactory healing.

All subjects, irrespective of the type of skin preparation performed, were given the same antibiotic: cloxacillin $500 \mathrm{mg}$ every six hours, starting one day pre-operatively and going on till the seventh post-operative day. The two subjects who developed SSI were given an additional antibiotic, cefuroxime $500 \mathrm{mg}$ twice a day for seven days.

Most of the participants who underwent surgery (62 [96.8\%]) were discharged from the hospital in less than three days, while the two participants (3.2\%) who had disturbances in healing stayed in the hospital for 7 days.

On the ASEPSIS scale, sixty-two subjects had a score of less than 10 indicating 'satisfactory healing' and 2 (3.1\%) had a score more than 10 indicating 'disturbance of healing.' The asepsis scores are shown in Figure 3 and the categories of wound healing obtained with the ASEPSIS score are given in Table 3.

\begin{tabular}{|c|c|c|c|c|}
\hline Details of Surgery & Category & Group A (Shaving) & Group B (Clipping) & Total \\
\hline Mode of hair removal & & $33(51.56 \%)$ & $31(48.44 \%)$ & 64 \\
\hline \multirow{2}{*}{ Surgery performed } & Left Tympanoplasty & $20(66.67 \%)$ & $10(33.33 \%)$ & 30 \\
\hline & Right Tympanoplasty & $12(35.29 \%)$ & $22(64.71)$ & 34 \\
\hline \multirow[t]{5}{*}{ Duration of surgery } & 1 hour 30 minutes - & & & \\
\hline & 1 hour 44 minutes & $12(50 \%)$ & $12(50 \%)$ & 24 \\
\hline & 1 hour 45 minutes - & & & \\
\hline & 1 hour 59 minutes & $14(52.86 \%)$ & $13(48.14 \%)$ & 27 \\
\hline & 2 hours and above & $7(53.85 \%)$ & $6(46.15 \%)$ & 13 \\
\hline \multirow[t]{3}{*}{ Irrigation of fluid } & Only Saline & $26(49.06 \%)$ & $27(50.94 \%)$ & 53 \\
\hline & Both Saline and & & & \\
\hline & Betadine & $7(63.63 \%)$ & $4(36.36 \%)$ & 11 \\
\hline \multirow{5}{*}{$\begin{array}{l}\text { Time elapsed between } \\
\text { hair removal and surgery }\end{array}$} & $<12$ hours & 0 & $2(100 \%)$ & 2 \\
\hline & $12-13$ hours & $3(75 \%)$ & $1(25 \%)$ & 4 \\
\hline & $13-14$ hours & $12(52.17 \%)$ & $11(47.83 \%)$ & 23 \\
\hline & $14-15$ hours & $12(48 \%)$ & $13(52 \%)$ & 25 \\
\hline & 15 hrs. and above & $4(40 \%)$ & $6(60 \%)$ & 10 \\
\hline \multirow[t]{4}{*}{ Antibiotic prophylaxis } & $\begin{array}{l}\text { Cloxacillin } 500 \text { mg every } 6 \text { th hourly } \\
\text { from } 1 \text { st day pre-op to } 7\end{array}$ & & & \\
\hline & days post-op & $33(53.23 \%)$ & $29(46.77 \%)$ & 62 \\
\hline & $\begin{array}{c}\text { Cloxacillin (as above) with cefuroxime } \\
500 \mathrm{mg} 12 \text { th hourly for }\end{array}$ & & & \\
\hline & \begin{tabular}{l|l}
7 additional days \\
\end{tabular} & 0 & 2 & 2 \\
\hline \multirow{2}{*}{ ASEPSIS score } & $<10$ & $33(53.23 \%)$ & $29(46.77 \%)$ & 62 \\
\hline & 10 and above & 0 & $2(6.45 \%)$ & 2 \\
\hline \multirow[t]{2}{*}{ Hospital stay } & $<3$ days & $33(53.23 \%)$ & $29(46.77 \%)$ & 62 \\
\hline & 3 days and above & 0 & $2(6.45 \%)$ & 2 \\
\hline \multicolumn{5}{|l|}{ Wound healing (ASEPSIS } \\
\hline \multirow{2}{*}{ Categories) } & Satisfactory & $33(53.23 \%)$ & $29(46.77 \%)$ & 62 \\
\hline & Disturbance of healing & 0 & $2(6.45 \%)$ & 2 \\
\hline
\end{tabular}

\begin{tabular}{|c|c|c|c|}
\hline ASEPSIS Score & $\begin{array}{l}\text { Group A } \\
\text { Clipping }\end{array}$ & $\begin{array}{c}\text { Group B } \\
\text { Shaving }\end{array}$ & P value \\
\hline$<10$ indicating satisfactory healing & $33(100 \%)$ & $29(93.5 \%)$ & \multirow{2}{*}{0.141} \\
\hline$>10$ indicating disturbance of healing & 0 & $2(6.5 \%)$ & \\
\hline \multicolumn{2}{|c|}{ Table 4. ASEPSIS Scores in Group A and Group B } \\
\hline
\end{tabular}




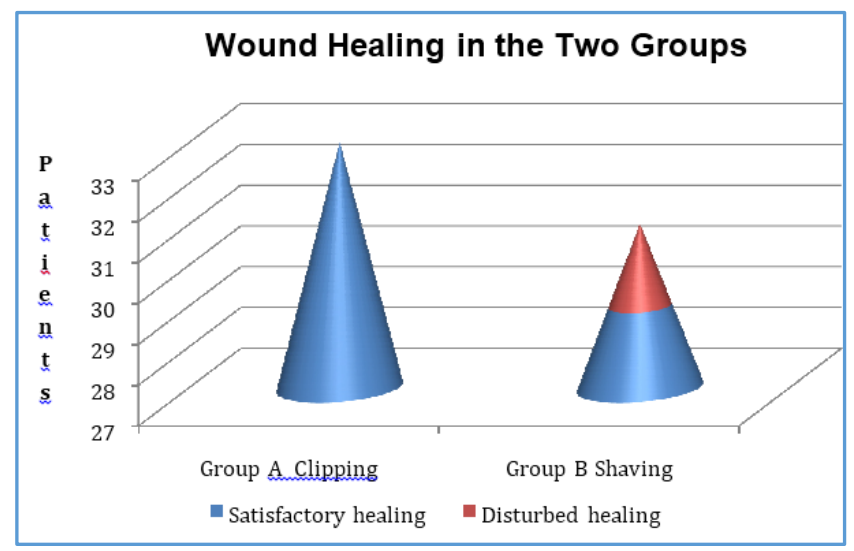

Figure 2. ASEPSIS Categories in Group A and Group B

\section{Legend}

Healing categories as indicated by the ASEPSIS scores.

\section{DISCUSSION}

Post-operative wound infection is a serious problem. Several strategies to decrease wound infections have been suggested including the use of prophylactic antibiotics, surgery in an aseptic operating room, improved surgical skills, skin preparation and so on. Studies have shown that hair removal with a razor or clippers can cause skin abrasion, even nicks which can lead to the development of pseudo-folliculitis and subsequent SSIs.[7] Out of the 64 subjects in our study, two developed disturbance of healing and both belonged to the group where the hair was removed by shaving.

According to the CDC Healthcare Infection Control Practices Advisory Committee (HICPAC), shaving with a razor before surgery is a well-documented risk factor for SSI and they recommend avoidance of hair removal before surgery whenever possible and the use of clippers if hair removal is necessary.

In the study by Bird et al, when pre-operative shaving was done infection of the wound was $2.9 \%$, while only $1.5 \%$ when shaving was not done.[15] In our study wound healing was satisfactory in all the patients where the hair was clipped with scissors, while there were two cases of disturbed healing in the group that had hair removal by shaving; however, this was not statistically significant $(\mathrm{p}=0.141)$.

In a study with 537 participants undergoing clean elective surgery, $9 \%$ of those who were shaved the day before surgery developed SSI compared with $10 \%$ who were shaved on the day of surgery. However, in this study the time of hair removal was not statistically significant.[7] In our study 29 (45.3\%) participants had hair removal less than 14 hours prior to surgery, while $35(54.7 \%)$ had hair removal more than 14 hours prior to surgery. Both the patients who developed disturbance of healing had a longer time interval between hair removal and surgery.

One subject who had a high ASEPSIS score was a 50-yearold male patient who had diabetes mellitus and was a smoker, while the other was a female under 20 years of age suffering from no other co-morbidities and with no other risk factors. This may give us a clue that risk factors like diabetes mellitus and smoking may predispose to disturbances in wound healing. However, no conclusions can be drawn as the numbers were few and statistical significance could not be obtained.
Both the participants who developed surgical site infection belonged to the low socioeconomic status group. Low socio-economic status is associated with lower levels of awareness of personal hygiene, unsanitary practices, nutritional status, educational status and this is an additional risk factor for delayed healing and ill-health.

Both these subjects had a haemoglobin concentration between 13 and $13.9 \mathrm{~g} \%$. Both underwent tympanoplasty lasting less than two hours and hence they are not relevant risk factors that may predict delayed healing.

Both these subjects who had disturbances in healing underwent surgery, in which irrigation was done using normal saline alone without additional povidone-iodine. Povidone-iodine is an antiseptic and there is not a single case of infection among the subjects in whom irrigation was done with both saline and povidone-iodine. This is a pointer that saline and povidone-iodine is a better irrigation fluid. However, no statistical significance can be attributed to this finding.

The influence of pre-operative shaving on the incidence of post-operative infection rates is well documented in literature.[7,16] Although, in this randomised controlled study there is no statistically significant difference between the methods of pre-operative hair removal during skin preparation on post-operative infection.

In our study, despite the two modes of hair removal, only two patients showed a disturbance of healing which was quickly dealt with and the patients could go home healed in seven days. There were no instances of minor, moderate or severe post-operative wound infection as graded by the ASEPSIS score.

In spite of the limitation that this trial studied only 64 patients undergoing surgery, it is commendable that strict adherence to asepsis at various stages of preparation, surgery and post-operative period have contributed to this very minimal post-operative healing disturbance. We have in our institution a very efficient Hospital Infection Control Committee, which supervises asepsis and systematically audits all hospital-acquired infections. They also suggest antibiotic protocols for the same.

The limitation of the small sample of only 64 subjects can be overcome by doing the same study on a larger scale or designing other studies to find out which mode of skin preparation is better. This could be done in many other surgical specialities, to check the healing of wounds based on the two modes of skin preparation. If these studies show significant results, a change of practice in the method of skin preparation can be advised as hospital protocol, leading to satisfactory healing, minimal risk of infection and maximum patient satisfaction.

\section{CONCLUSION}

In this study of 64 patients undergoing tympanoplasty, it was found that 62 participants had satisfactory healing as graded by the ASEPSIS score and 2 participants had disturbance of healing. There were no patients who had mild, moderate or severe surgical site infection as graded by the ASEPSIS score.

Additional factors observed were that both the subjects who developed disturbance of wound healing belonged to the lower socioeconomic strata of society. Both had wound irrigation done using normal saline alone. 


\section{Jemds.com}

This study shows that good preoperative preparation and strict enforcement of aseptic precautions can reduce the number of surgical site infections irrespective of the method of hair removal.

\section{REFERENCES}

[1] Sharma M, Joshi R, Shah H, et al. A step-wise approach towards introduction of an alcohol-based hand rub, and implementation of front-line ownership- using a rural tertiary care hospital in central India as a model. BMC Health Serv Res 2015;15:182.

[2] Mawalla B, Mshana SE, Chalya PL, et al. Predictors of surgical site infections among patients undergoing major surgery at Bugando Medical Centre in Northwestern Tanzania. BMC Surg 2011;11:21.

[3] Tanner J, Norrie P, Melen K. Preoperative hair removal to reduce surgical site infection. Cochrane Database Syst Rev 2011;9(11):CD004122.

[4] Orsi GB, Ferraro F, Franchi C. Preoperative hair removal review. Ann Ig 2005;17(5):401-12.

[5] Karegoudar JS, Prabhakar P J, Vijayanath V, et al. Shaving versus depilation cream for pre-operative skin preparation. Indian J Surg 2012;74(4):294-7.

[6] Guideline for surgical skin disinfection. Version 2 Dec 2012. Department of Health, Queensland. https://www.health.qld.gov.au/chrisp/ic.../Guideline_ CHRISP_01.pdf

[7] Mangram AJ, Horgan TC, Pearson ML, et al. Guideline for prevention of surgical site infection, 1999. Hospital Infection Control Practices Advisory Committee. Infect Control Hospital Epidemiolo 1999;20(4):250-78.

\section{Original Research Article}

[8] WHO. Surgical hand preparation: state of the art Guidelines on Hand Hygiene in Health Care - Evidence for surgical hand preparation. NCBI Bookshelf, 2015.

[9] Dumville JC, McFarlane E, Edwards P, et al. Preoperative skin antiseptics for preventing surgical wound infections after clean surgery. Cochrane database Syst Rev 2013;(3):CD003949.

[10] Singh S, Chakravarthy M, Rosenthal VD, et al. Surgical site infection rates in six cities of India: findings of the International Nosocomial Infection Control Consortium (INICC). Int Health 2015;7(5):354-9.

[11] Gagliardi AR, Fenech D, Eskicioglu C, et al. Factors influencing antibiotic prophylaxis for surgical site infection prevention in general surgery: a review of the literature. Can J Surg 2009;52(6):481-9.

[12] Ashby E, Haddad FS, O'Donnell E, et al. How will surgical site infection be measured to ensure "high quality care for all"? J Bone Joint Surg 2010;92(9):1294-9.

[13] Wilson APR, Treasure T, Sturridge MF, et al. A scoring method (ASEPSIS) for postoperative wound infections for use in clinical trials of antibiotic prophylaxis. The Lancet 1986;1(8476):311-3.

[14] nMaster Sample Size Calculation Software, produced by The Biostatistics Department, Christian Medical College, Vellore: 632004.

[15] Bird BJ, Chrisp DB, Scrimgeour G. Extensive preoperative shaving: a costly exercise. N Z Med J 1984;97(766):727-9. 